\title{
Removal Process of Nutrients and Heavy Metals in Tropical Biofilters
}

\author{
Andreas Aditya Hermawan ${ }^{1 *}$, Da Yoon Jung ${ }^{1}$, Amin Talei ${ }^{1 *}$ \\ ${ }^{1}$ The discipline of Civil Engineering, Monash University Malaysia, Jalan Lagoon Selatan, Bandar \\ Sunway, 47500 Subang Jaya, Selangor, Malaysia
}

\begin{abstract}
Biofilters are relatively new pollution control technology used to treat urban stormwater runoffs. Biofilters generally consist of vegetated top soil layer for nutrient uptake and sand-based filter media for heavy metals filtration. While the complex process of pollutant removal is studied for a temperate environment, only a few studies have been conducted under tropical climate conditions. This study aims to study the removal process of total nitrogen, total phosphorus and 6 heavy metals including copper, iron, manganese, nickel, lead, and zinc in a tropical biofiltration system. In this study, using the curve fitting analysis, the parabolic function was found to be the most fitted function to explain the relationship between pollutant concentration in the effluent and the infiltration rate of the system when the first flush phenomenon is simulated. Results demonstrated that the natural variation of infiltration rate during the saturation process of soil influences the performance of the system in removing some pollutants such as phosphorus, iron, and zinc.
\end{abstract}

\section{Introduction}

Bioretention systems also known as biofilters are the most commonly used stormwater treatment as the 'best management practice' in many countries in the world [1]. Development increases areas of impervious surfaces such as roads, parking lots, and roofs preventing a large amount of precipitation from infiltrating into the soil and therefore, stormwater runoffs in urban areas need to be treated with care. Urban stormwater runoff consisting various range of pollutants such as sediments, heavy metals, nutrients and oil and grease that brings negative impacts on receiving waters [2]. Heavy metals mainly come from vehicles, roads and industrial areas. They are an important pollutant to tackle in urban areas due to their high toxicity at low concentration and the possibility of accumulation in living organisms [3]. Nitrogen and phosphorus are the primary nutrients responsible for eutrophication which enters the water bodies from agricultural runoff, point sources and urban and septic discharges [4].

Past researches have proved the effectiveness of biofilters in reducing effluent loads for suspended solids, nutrients, and heavy metals $[1,5]$. Biofilters can slow down stormwater runoff rates, reduce the runoff volumes, and filter pollutants before the water is discharged

Corresponding author: andreas.aditya1@monash.edu 
into any receiving waters. The process involves filtration, absorption, vegetation uptake, and biotransformation. The heavy metals are filtered by the top soil filter layer while the nutrients are filtered by plants uptake [6]. Gravel layer is set at the bottom of the system to promote drainage and there is usually a transition layer with intermediate grain sizes between the filter media and the gravel layer to minimize the loss of the filter media from being washed away [7].

However, the removal process of nutrients and heavy metals in biofiltration is complex with many factors to consider and currently, there is a knowledge gap on the performance of biofiltration systems in tropical areas with different climate patterns and different behaviours of local soil and plants [1,8]. Local plants with different root sizes may also affect the efficiency of the system by the creation of micropores and thus changing the hydraulic conductivity [9]. The high intensity and frequent rainfall in tropical climates also need to be considered in the design criteria for biofiltration systems. The current bioretention basin design guidelines for tropics need to be revised according to the local context. Moreover, further research is needed to understand the effects of different parameters on the performance of the system in tropical condition and provide recommendations for the optimum use of it [10].

This research study has been undertaken to develop an analytical model on the removal process of nutrients and heavy metals in an experimental soil column biofiltration system under tropical condition. The removal processes of total nitrogen (TN), total phosphorous (TP) and 6 heavy metals: zinc $(\mathrm{Zn})$, copper $(\mathrm{Cu})$, lead $(\mathrm{Pb})$, nickel $(\mathrm{Ni})$, iron $(\mathrm{Fe})$ and manganese $(\mathrm{Mn})$ have been analyzed to develop an analytical relationship between infiltration rate and outlet pollutants concentration.

\section{Methodology}

\subsection{Experimental setup}

A total of 16 biofilter columns constructed from PVC pipes with $200 \mathrm{~mm}$ diameter and $1000 \mathrm{~mm}$ height were used in this experiment. The inner surface of the columns was first scratched using sand paper to minimize the possibility of unwanted preferential flow pathways for inflow water. The inner structure of the columns is shown in Figure 1(a) where it includes $165 \mathrm{~mm}$ of freeboard, $400 \mathrm{~mm}$ of filter media consisting of fine to medium sand, $100 \mathrm{~mm}$ of transition layer consisting of coarse to very coarse sand and lastly $335 \mathrm{~mm}$ of drainage layer consisting of fine to coarse gravel. Fine to coarse gravels are placed at the bottom of the column to promote drainage in the system. The transition layer between the filter media and drainage layer prevents the filter media from washing away. Out of the 16 columns, 6 columns are made using transparent PVC pipe with detachable cover to observe the root growth for plants. The experiment setup for the study is found in Figure 1(b). Four native plants were chosen which follows the characteristics of the plants recommended by Urban Stormwater Management Manual for Malaysia (Manual Saliran Mesra Alam Malaysia, MSMA) while 3 replicates for each column-plant were prepared [10]. The four plants are Ti plant (Cordyline fruticosa) denoted as CF, Rosea variegata (Graptophyllum pictum) denoted as GP, Bamboo grass (Bambusoideae) denoted as BE and Umbrella plant (Cyperus alternifolius) denoted as CA which can be found in Figure 2. 


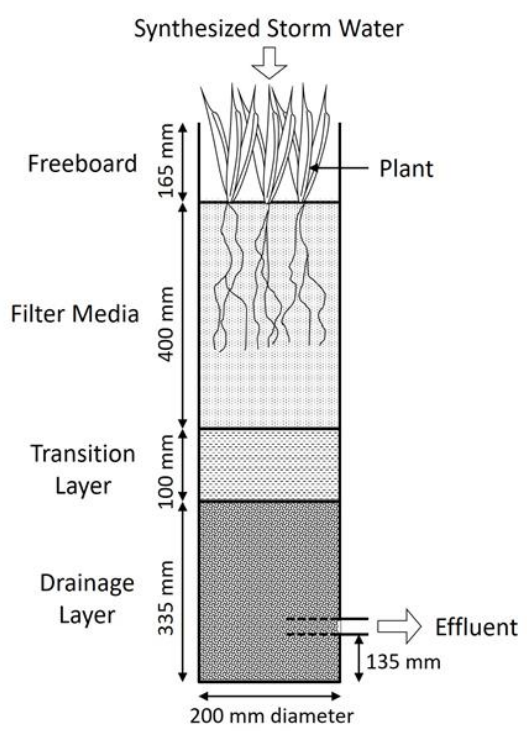

(a)

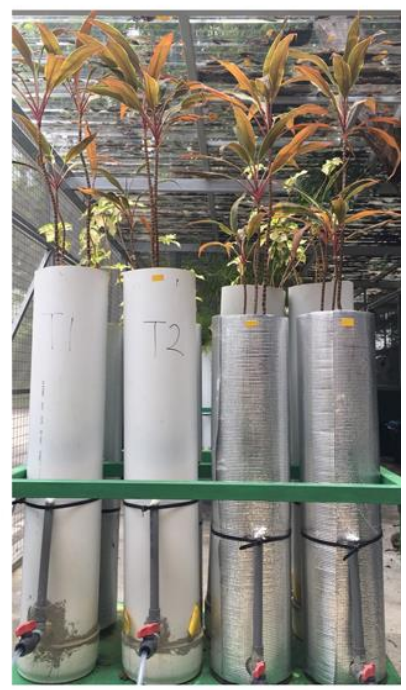

(b)

Fig. 1. Biofilter columns: (a) inner structure and (b) experimental setup of biofiltration columns.

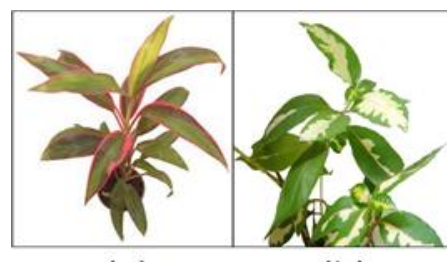

(a)

(b)

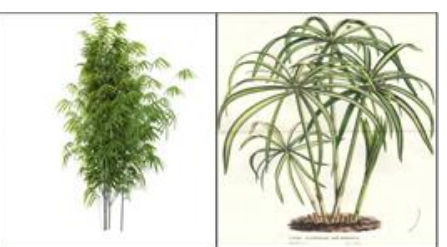

(c)

(d)

Fig. 2. Plants for soil columns: (a) Ti plant (Cordyline fruticosa); (b) Rosea variegate (Graptophyllum pictum); (c) Bamboo grass (Bambusoideae); (d) Umbrella plant (Cyperus alternifolius).

\subsection{Filter media}

The particle size of each layer in the biofilter column has been designed by fulfilling the particle size distribution criteria proposed for the filter, transition, and drainage layer to prevent the finer particles being washed into the coarser particles during the experiment [11]. The two criteria are given in Eqs. (1) and (2):

$$
\begin{gathered}
D_{15}(\text { Transition }) \leq D_{85}(\text { Filter }) \\
D_{15}(\text { Drainage }) \leq D_{85}(\text { Transition })
\end{gathered}
$$

where $D_{15}$ and $D_{85}$ are the 15 th and 85 th percentile particle size respectively. The available river sand in the local market was used following the soil composition is shown in Table 1. 
Table 1. Soil composition for column study experiments.

\begin{tabular}{llll}
\hline \multirow{2}{*}{ Particle size $(\mathrm{mm})$} & \multicolumn{3}{c}{ Percentile distribution (\%) } \\
\cline { 2 - 4 } & Drainage & Transition & Filter \\
\hline$>4.75$ & 30 & - & - \\
$3.35-4.75$ & 55 & - & - \\
$2.36-3.35$ & 10 & 25 & - \\
$1.18-2.36$ & 5 & 60 & 10 \\
$0.60-1.18$ & - & 10 & 20 \\
$0.30-0.60$ & - & 5 & 55 \\
$<0.30$ & - & - & 15 \\
\hline
\end{tabular}

\subsection{Synthesized stormwater}

Synthesized stormwater is used to maintain the consistency in the chemical and physical characteristics of stormwater. The synthesized stormwater concentration was adopted from past studies on Malaysia and world average stormwater data [12, 13]. The concentration for each pollutant is shown in Table 2. As a comparison, Class IIB and Class IV Malaysia water standard are used. Class IIB is appropriate for recreational body contact while class IV is appropriate for irrigation purposes [14].

Table 2. The concentration of pollutants in synthesized stormwater.

\begin{tabular}{llll}
\hline Pollutant & $\begin{array}{l}\text { Initial conc. } \\
(\mathrm{ppm})\end{array}$ & $\begin{array}{l}\text { Class II } \\
(\mathrm{ppm})\end{array}$ & $\begin{array}{l}\text { Class IV } \\
(\mathrm{ppm})\end{array}$ \\
\hline $\mathrm{TN}$ & 4.32 & 7.7 & 8.7 \\
$\mathrm{TP}$ & 1.12 & 0.2 & - \\
$\mathrm{Cu}$ & 0.15 & 0.02 & - \\
$\mathrm{Fe}$ & 0.86 & 1.0 & 1.0 \\
$\mathrm{Mn}$ & 0.23 & 0.1 & 0.2 \\
$\mathrm{Ni}$ & 0.03 & 0.05 & 0.2 \\
$\mathrm{~Pb}$ & 0.14 & - & - \\
$\mathrm{Zn}$ & 0.25 & 5 & 2 \\
\hline
\end{tabular}

\subsection{Sampling and Testing}

Sampling is done by pouring synthesized stormwater in the columns and collecting the samples in volumetric time series manner. The dosage used in this study is 13 liters based on the Malaysian guidelines [10]. The standard constant-head method was used for infiltration rate test with measurement gap of $500 \mathrm{ml}$ of effluent up to $4000 \mathrm{ml}$ [15]. For water quality test, 4 intervals were set including $0,500,1500$ and $4000 \mathrm{ml}$ of effluent. Considering the three rounds of sampling and the 3 replicates of each column-plant, a total of 9 data points was collected for each volumetric value in each column type for further analysis.

The water quality testing was carried out using three different parameters: heavy metals, TN and TP. Inductively Coupled Plasma Optical Emission Spectroscopy (ICP-OES) with the detection limit of $0.001 \mathrm{mg} / \mathrm{L}$ was used for the heavy metals. For TN and TP, DR3900 
and DR6000 were used as UV-VIS Spectroscopy with the detection limit of $0.01 \mathrm{mg} / \mathrm{L}$. HACH persulfate digestion methods 10071 and 8190 are used for TN and TP respectively.

\subsection{Analytical modeling}

A data analysis was conducted to identify the outliers from the collected data points. Then curve fitting analysis was carried out to identify an analytical relationship between the collected volume of water and effluent concentration for each individual plant and pollutant. The proposed mathematical functions were then verified using efficiency and error measures including coefficient of determination $\left(\mathrm{R}^{2}\right)$, mean absolute error (MAE) and root mean square error (RMSE) using Eqs. (3-5).

$$
\begin{aligned}
R^{2} & =1-\frac{\sum(y-\hat{y})^{2}}{\sum(y-\bar{y})^{2}} \\
\mathrm{MAE} & =\frac{1}{n} \sum_{j=1}^{n}\left|y_{j}-\hat{y}_{j}\right| \\
\mathrm{RMSE} & =\sqrt{\frac{1}{n} \sum_{j=1}^{n}\left(y_{j}-\hat{y}_{j}\right)^{2}}
\end{aligned}
$$

where $\mathrm{y}$ is the actual value, $\hat{\mathrm{y}}$ is the predicted $\mathrm{y}$ value obtained from trendline, $\overline{\mathrm{y}}$ is the mean of the $\mathrm{y}$ values and $\mathrm{n}$ is the number of data used in the function.

\section{Results and discussion}

\subsection{Infiltration rate results}

Increasing infiltration rate is observed at $1500 \mathrm{ml}$ volume collection for all plants before stabilizing as shown in Figure 3. The saturation of the system is indicated by the stabilized infiltration rate. As the water starts to saturate the soil, there is a decrease in the air pressure when entrapped soil air escapes from the surface and this results in the initial increase of the infiltration rate [16]. The escape of the entrapped soil air can be observed by the presence of air bubbles on the surface of the columns. It was also reported that the eruption of the soil particles during the escape of air bubbles created small openings in the soil surface which could be another reason for the increase in infiltration rate [16]. However, when the system is saturated and air escape stopped, the stabilization of infiltration rate is observed.

Overall, plant CF shows the highest infiltration rate of $1247 \mathrm{~mm} / \mathrm{h}$ followed by $\mathrm{BE}$ $(1187 \mathrm{~mm} / \mathrm{h})$, GP $(959 \mathrm{~mm} / \mathrm{h})$ and CA $(958 \mathrm{~mm} / \mathrm{h})$. The different root sizes of plants are responsible for the difference in the infiltration rate [9]. According to biofiltration guidelines, the ideal infiltration rate for drainage purposes in biofiltration system is between 100 to $300 \mathrm{~mm} / \mathrm{h}$ [17]. The observed infiltration rate from the experiment is much higher than the recommendation. It is expected to be due to the vegetation roots penetrating through soils forming macro-pores where past study has shown that the vegetation of biofilters directly affects the hydrologic performance of the system [18]. 


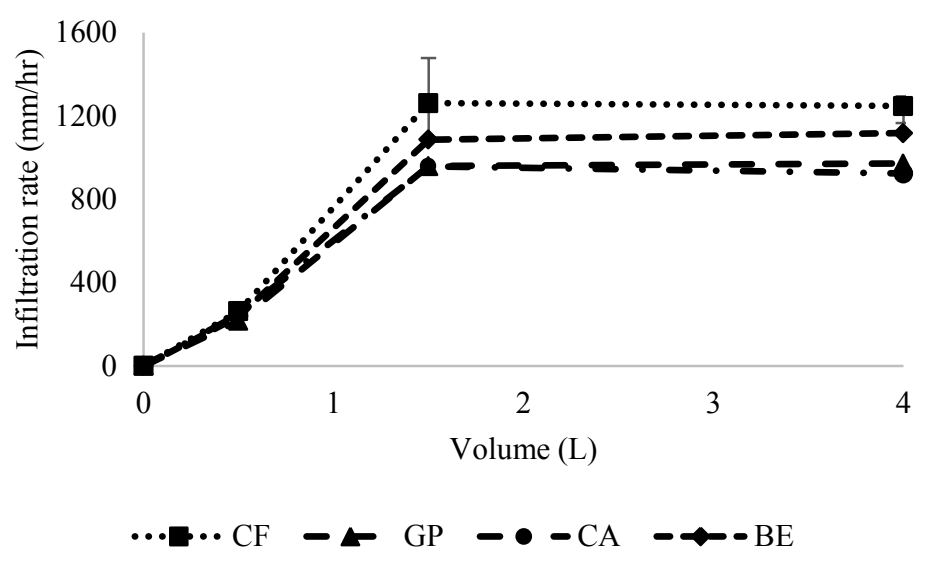

Fig. 3. Infiltration rate of plants $\mathrm{CF}, \mathrm{GP}, \mathrm{CA}$ and $\mathrm{BE}$.

\subsection{Pollutant removal}

The results on the effluent concentration for each plant can be seen in Table 3. All the pollutants concentration falls under class IIB except for TP. Out of the four plants, plant CA showed the lowest TP concentration $(0.21 \mathrm{ppm})$ while plant GP showed the highest TP concentration $(0.46 \mathrm{ppm})$. The difference of effluent TP concentration can be attributed to the plant's uptake [19-21]. Since GP is the smallest plant with thinnest roots, it is expected to have lower TP uptake compared with CA with thick and long roots. For TN uptake, all four plants are able to remove only $40.3-45.5 \%$ from the influent concentration value. This finding is similar to the previous study which reported poor TN removal due to the presence of excess nitrogen from the required nutrients uptake [22]. Although in this experiment all plants show similar performance in removing $\mathrm{TN}$, a different finding was observed in a similar study which concluded that grass family plants (BE in this study) should remove less TN due to its minimum uptake [23]. It is expected that massive growth of the BE contributes to the similar TN removal performance of plant BE compared with other plants.

Table 3. Effluent concentration from biofiltration columns.

\begin{tabular}{|c|c|c|c|c|c|c|c|c|c|}
\hline \multirow{3}{*}{$\begin{array}{c}\text { Pollutant } \\
\text { TN }\end{array}$} & \multirow{3}{*}{$\begin{array}{c}\begin{array}{c}\text { Influent } \\
\text { conc. } \\
(\mathrm{ppm})\end{array} \\
4.320\end{array}$} & \multicolumn{8}{|c|}{ Effluent concentration (ppm) / removal percentage (\%) } \\
\hline & & \multicolumn{2}{|c|}{$\mathbf{C F}$} & \multicolumn{2}{|c|}{ GP } & \multicolumn{2}{|c|}{$\mathbf{C A}$} & \multicolumn{2}{|c|}{ BE } \\
\hline & & 2.360 & 45.5 & 2.500 & 42.1 & 2.430 & 43.7 & 2.580 & 40.3 \\
\hline TP & 1.120 & 0.240 & 78.8 & 0.460 & 59.3 & 0.210 & 81.1 & 0.270 & 75.8 \\
\hline $\mathbf{Z n}$ & 0.250 & 0.010 & 96.0 & 0.010 & 96.0 & 0.010 & 96.0 & 0.011 & 95.6 \\
\hline $\mathbf{P b}$ & 0.140 & 0.005 & 96.4 & 0.006 & 95.7 & 0.005 & 96.4 & 0.007 & 95.0 \\
\hline $\mathbf{N i}$ & 0.030 & 0.002 & 93.3 & 0.002 & 93.3 & 0.002 & 93.3 & 0.002 & 93.3 \\
\hline $\mathbf{F e}$ & 0.860 & 0.202 & 76.6 & 0.171 & 80.1 & 0.222 & 74.2 & 0.469 & 45.5 \\
\hline Mn & 0.230 & 0.006 & 97.4 & 0.004 & 98.3 & 0.010 & 95.7 & 0.007 & 97.0 \\
\hline $\mathbf{C u}$ & 0.150 & 0.011 & 92.7 & 0.010 & 93.3 & 0.010 & 93.3 & 0.011 & 92.7 \\
\hline
\end{tabular}


On the other hand, significant removal of heavy metals is achieved by all plants. From Table 3, the removal of $\mathrm{Zn}, \mathrm{Pb}, \mathrm{Ni}, \mathrm{Mn}$, and $\mathrm{Cu}$ are more than $90 \%$ from the influent value. However, Fe removal varies between each plant as BE is only removing $45.5 \%$, while GP has the highest removal rate at $80.1 \%$. The difference in the results is attributed to the infiltration rate value where the lower infiltration rate value (GP) has longer retention time thus removing more Fe than plant BE.

The distribution of the data points for each pollutant and plant is presented in boxplot as shown in Figure 4. From the range, It can be observed that most of the heavy metals concentration are stable throughout the duration of the experiment, except for Mn. Plant CA has the highest fluctuation of Mn during the experiment due to the effect of the deep plant root [24]. As for nutrients data distribution, there is small variance to the value for each plant and thus the results are considered as reliable.

\subsection{Analytical solution}

After a preliminary data analysis on the collected data, the parabolic function was found to be the most fitted function to the experimental data. In this analytical analysis, the target is to develop a relationship between the concentration of pollutants in effluent and the collected volume of infiltrated water from the outlet which indirectly represents the infiltration rate. This equation can be shown as Eq. (8).

$$
\mathrm{y}=a x^{2}+b x+c
$$

where $\mathrm{y}$ denotes the concentration of pollutant in the effluent (ppm) and $\mathrm{x}$ denotes the volume of effluent collected (in litreliterble 5 summarizes the values of variables a, b and c with the respective $\mathrm{R}^{2}$, RMSE a value that out of the 8 pollutants tested, only 3 pollutants $\mathrm{Zn}$ and shows a pattern that could draw to a single representable equation with correlation coefficient higher than 0.5 . TN does not show any pattern for its removal efficiency thus cannot be model using Eq. (8). On the other hand, $\mathrm{Pb}, \mathrm{Ni}, \mathrm{Mn}$, and $\mathrm{Cu}$ are also excluded from the modeling to their low effluent concentration (see Table 3) with respect to volume series.

Table 5. Summary of analytical modeling results

\begin{tabular}{llllllcc}
\hline Pollutant & Plant & $\mathrm{a}$ & $\mathrm{b}$ & $\mathrm{c}$ & $\mathrm{R}^{2}$ & $\begin{array}{c}\text { RMSE } \\
(\mathrm{ppm})\end{array}$ & $\begin{array}{c}\mathrm{MAE} \\
(\mathrm{ppm})\end{array}$ \\
\hline \multirow{3}{*}{$\mathrm{TP}$} & $\mathrm{CF}$ & -0.020 & 0.097 & 0.176 & 0.601 & 0.031 & 0.113 \\
& $\mathrm{GP}$ & -0.013 & 0.076 & 0.345 & 0.311 & 0.058 & 0.125 \\
& $\mathrm{CA}$ & -0.019 & 0.097 & 0.132 & 0.822 & 0.019 & 0.091 \\
& $\mathrm{BE}$ & -0.030 & 0.146 & 0.199 & 0.543 & 0.051 & 0.166 \\
& & & & & & & \\
$\mathrm{Fe}$ & $\mathrm{CF}$ & -0.122 & 0.525 & 0.001 & 0.903 & 0.058 & 0.416 \\
& $\mathrm{GP}$ & -0.116 & 0.470 & 0.071 & 0.676 & 0.121 & 1.769 \\
& $\mathrm{CA}$ & -0.179 & 0.749 & 0.005 & 0.959 & 0.053 & 0.239 \\
& $\mathrm{BE}$ & -0.260 & 1.082 & 0.223 & 0.533 & 0.374 & 2.700 \\
$\mathrm{Zn}$ & & & & & & & \\
& $\mathrm{CF}$ & -0.001 & 0.003 & 0.009 & 0.552 & 0.010 & 0.066 \\
& $\mathrm{GP}$ & -0.001 & 0.003 & 0.009 & 0.645 & 0.001 & 0.070 \\
& $\mathrm{CA}$ & -0.001 & 0.005 & 0.011 & 0.512 & 0.002 & 0.125
\end{tabular}



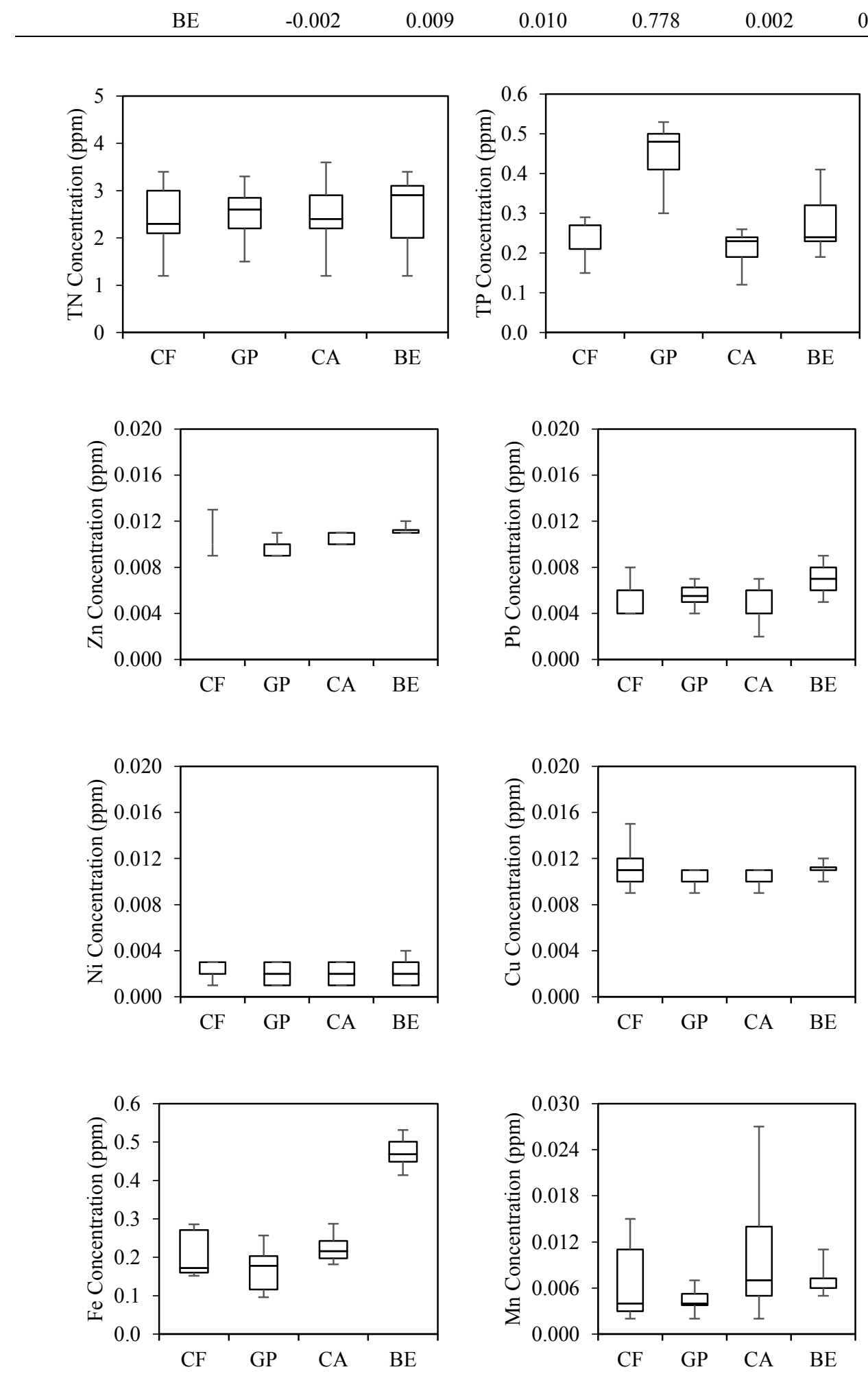
Fig. 4. Boxplot for effluent pollutants concentration.

For the model of TP removal, plant CA shows the highest $\mathrm{R}^{2}$ value $(0.822)$ with the lowest RMSE (0.019) and MAE (0.091) compared to other 3 plants. Similarly, for Fe model, plant CA shows the highest $\mathrm{R}^{2}$ value $(0.959)$ with the lowest RMSE $(0.053)$ and MAE (0.239). For $\mathrm{Zn}$ model, plant BE shows the highest $\mathrm{R}^{2}$ value of 0.778 with relatively low RMSE at 0.0017 and MAE values of 0.089 . The concentration of the pollutants in the effluent is increased with respect to the volume of effluent collected. This matches with the results discussed in the infiltration rate test where the increase in the infiltration rate will reduce the removal efficiency of the pollutants due to shortening of the contact time between the pollutants and the filter media [25]. However, as the system becomes saturated, the infiltration rate is decreased and started to stabilize, providing enough retention time for the pollutants to be treated. It is observed from the models that the pollutant concentration in the effluent will decrease as the infiltration rate of the system stabilizes. Another reason for the initial increase of the concentration can be due to the leaching of accumulated pollutants in the system due to the previous round of watering. Therefore, the initial effluent collected is expected to contain both its own pollutants and the accumulated pollutants resulting in high concentration. However, at volume $0 \mathrm{ml}$, the effluent concentration is very close to $0 \mathrm{ppm}$ and this can be explained by past studies where heavy metals accumulation happen at the top of the filter [19]. Based on the analysis, it can be seen that the study is correlated with the first flush phenomenon. However, since this study uses synthesized stormwater with constant pollutant concentration, it is expected that the effluent concentration stabilized after increasing without decreasing pattern [26].

\section{Conclusion}

The present study examines the nutrients and heavy metals removal performance of tropical biofilters in relation to the infiltration rate of the system. The infiltration rate of the biofilter column is increased until the system reaching saturation and then stabilized. Among the four plants tested, Cordyline fruticosa shows the highest infiltration of $1247 \mathrm{~mm} / \mathrm{h}$. The pollutant removal performance in biofilters is found to be dependent on the infiltration rate of the system where an increase in the infiltration rate during the saturation process decreases the removal efficiency of the system. However, after the system is saturated, the removal efficiency increases while the infiltration rate remains constant. The removal of $\mathrm{TP}, \mathrm{Fe}$, and $\mathrm{Zn}$ can be modeled by a parabolic function with respect to the volume of effluent collected. Fe model of Cyperus alternifolius showed the highest coefficient of determination of 0.959 . Overall, the study can be correlated with the first flush effect by looking into the increasing pattern of effluent concentration before reaching stabilization.

\section{References}

1. Davis, A.P., et al., Bioretention technology: Overview of current practice and future needs. Journal of Environmental Engineering, 2009. 135(3): p. 109-117.

2. Laurenson, G., et al., The role of bioretention systems in the treatment of stormwater, in Advances in agronomy. 2013, Elsevier. p. 223-274.

3. Joshi, U. and R. Balasubramanian, Characteristics and environmental mobility of trace elements in urban runoff. Chemosphere, 2010. 80(3): p. 310-318.

4. Davis, A.P., et al., Water quality improvement through bioretention media: Nitrogen and phosphorus removal. Water Environment Research, 2006. 78(3): p. 284-293. 
5. Dietz, M.E., Low impact development practices: A review of current research and recommendations for future directions. Water, air, and soil pollution, 2007. 186(14): p. 351-363.

6. Davis, A.P., et al., Laboratory study of biological retention for urban stormwater management. Water Environment Research, 2001: p. 5-14.

7. Lim, H.S., et al., Comparison of filter media materials for heavy metal removal from urban stormwater runoff using biofiltration systems. Journal of Environmental Management, 2015. 147: p. 24-33.

8. Muha, N.E. and L.M. Sidek, Bio-retention system as storm water quality improvement mechanism. Sci Res J, 2015. 3(2): p. 39-46.

9. Le Coustumer, S., et al., The influence of design parameters on clogging of stormwater biofilters: A large-scale column study. Water Research, 2012. 46(20): p. 6743-6752.

10. MSMA, Manual Saliran Mesra Alam. 2012, Department of Irrigation and Drainage: Kuala Lumpur, Malaysia.

11. Payne, E., et al., Adoption guidelines for stormwater biofiltration systemsSummary report. Cooperative Research Centre for Water Sensitive Cities, Melbourne, Australia, 2015.

12. Duncan, H., Urban stormwater quality: a statistical overview. 1999: CRC for Catchment Hydrology.

13. Yusop, Z., et al., Runoff quality and pollution loadings from a tropical urban catchment. Water Science \& Technology, 2005. 52(9): p. 125-132.

14. DOE, Malaysia Environmental Quality Report. 2006, Department of Environment: Malaysia.

15. ASTM D2434-68, Standard Test Method for Permeability of Granular Soils (Constant Head). 2006, ASTM International: West Conshohocken.

16. Wang, Z., et al., Air entrapment effects on infiltration rate and flow instability. Water Resources Research, 1998. 34(2): p. 213-222.

17. FAWB, Adoption Guidelines for Stormwater Biofiltration Systems, Facility for Advancing Water Biofiltration. Vol. version 1. 2009, Monash University.

18. Devitt, D.A. and S.D. Smith, Root channel macropores enhance downward movement of water in a Mojave Desert ecosystem. Journal of Arid Environments, 2002. 50(1): p. 99-108.

19. Hatt, B.E., T.D. Fletcher, and A. Deletic, Hydraulic and pollutant removal performance of fine media stormwater filtration systems. Environmental science \& technology, 2008. 42(7): p. 2535-2541.

20. Henderson, C., M. Greenway, and I. Phillips, Removal of dissolved nitrogen, phosphorus and carbon from stormwater by biofiltration mesocosms. Water Science \& Technology, 2007. 55(4): p. 183-191.

21. Bratieres, K., et al., Nutrient and sediment removal by stormwater biofilters: $A$ large-scale design optimization study. Water Research, 2008. 42(14): p. 39303940.

22. Read, J., et al., Variation among plant species in pollutant removal from stormwater in biofiltration systems. Water Research, 2008. 42(4-5): p. 893-902.

23. Ozawa, M., et al., Effects of surface soil removal on dynamics of dissolved inorganic nitrogen in a snow-dominated forest. The Scientific World Journal, 2001. 1: p. 527-533.

24. Clarkson, D.T., The uptake and translocation of manganese by plant roots, in Manganese in soils and plants. 1988, Springer. p. 101-111. 
25. Sousa, F.W., et al., Green coconut shells applied as adsorbent for removal of toxic metal ions using fixed-bed column technology. Journal of environmental management, 2010. 91(8): p. 1634-1640.

26. Lee, J., et al., First flush analysis of urban storm runoff. Science of the Total Environment, 2002. 293(1): p. 163-175. 